\title{
USING SAR INTERFEROGRAMS AND COHERENCE IMAGES FOR OBJECT-BASED DELINEATION OF UNSTABLE SLOPES
}

\author{
Barbara Friedl $^{(1)}$, Daniel Hölbling ${ }^{(1)}$ \\ ${ }^{(1)}$ Interfaculty Department of Geoinformatics - Z_GIS, University of Salzburg, 5020 Salzburg, Austria, Email: \\ barbara.friedl@sbg.ac.at, daniel.hoelbling@sbg.ac.at
}

\begin{abstract}
This study uses synthetic aperture radar (SAR) interferometric products for the semi-automated identification and delineation of unstable slopes and active landslides. Single-pair interferograms and coherence images are therefore segmented and classified in an object-based image analysis (OBIA) framework. The rule-based classification approach has been applied to landslide-prone areas located in Taiwan and Southern Germany. The semi-automatically obtained results were validated against landslide polygons derived from manual interpretation.
\end{abstract}

\section{INTRODUCTION}

Traditionally, slope instabilities are monitored using ground-based methods such as tacheometry, precise levelling and global positioning system (GPS) surveying. However, these techniques are timeconsuming, cost-intensive and limited regarding spatial and temporal coverage [1]. Further, only point measurements are provided, minimizing the possibility of adequately depicting the dynamics of complex natural phenomena. The increasing amount of nowadays available Earth observation (EO) data has led to the evolution of novel techniques for the mapping and monitoring of unstable slopes. Especially synthetic aperture radar (SAR) interferometry has proven to be powerful for detecting and monitoring small-scale surface deformations associated with slope instabilities with a centimetre to millimetre accuracy. However, a quantitative exploration of interferometric SAR results with semi-automated methods is commonly still lacking. Taking up this consideration, the main aim of the proposed study is to semi-automatically identify and delineate unstable slopes based on single pair SAR interferograms and coherence images using objectbased image analysis (OBIA).

\subsection{Object-based image analysis for landslide mapping}

By interlinking image segmentation and classification OBIA is making progress towards a spatially explicit information extraction workflow [2]. OBIA has been successfully applied for semi-automated landslide detection, particularly on optical remote sensing data and digital elevation information, e.g. as described in
$[3,4,5]$, as it supports the use of spectral, spatial, textural as well as contextual properties during image analysis. Since OBIA is addressing objects, rather than individual pixels, it is well suited for analysing complex natural phenomena such as landslides. In addition, OBIA allows the integration of multiple remote sensing or other image-like data, allowing the exploitation of a plethora of image properties. However, comparatively few studies, e.g. [6], addressed the applicability of OBIA for landslide analysis based on SAR data or SAR interferometric products.

\section{STUDY SITE AND DATA}

The developed approach was tested in two study sites with distinct environmental settings and frequent landslide activity. The first test area is located in the Kaoping watershed in Southern Taiwan and is strongly affected by rainfall-induced landslides due to its particular climatic and geologic setting. The area won notoriety on 9 August 2009, when Typhoon Morakot triggered the catastrophic Xiaolin Landslide, which caused 465 casualties [7] and severe damages to infrastructure. The second study site is situated in the alpine terrain of Upper Bavaria, Southern Germany, and experiences gravitational mass movements mainly after periods of intense and prolonged rainfall. Fig. 1 displays landslides within the study area in Taiwan; Fig. 2 shows landslides in the German test site.

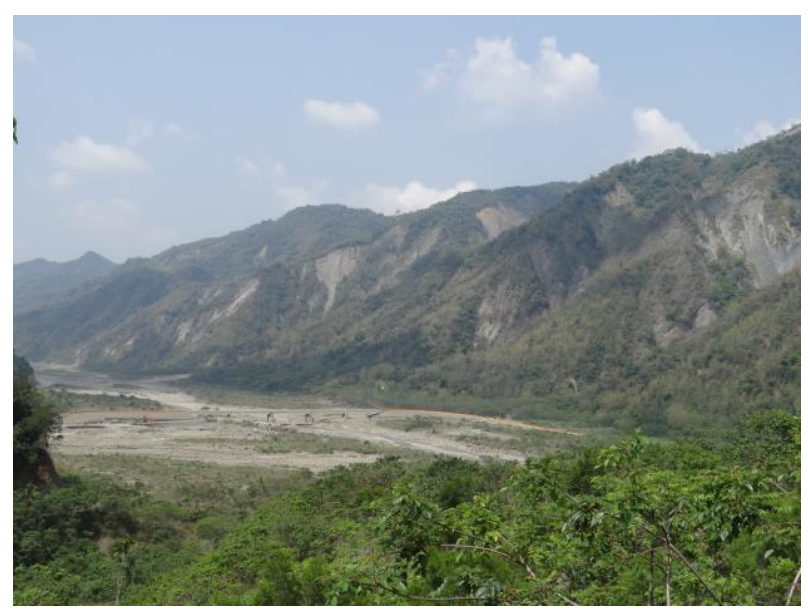

Figure 1. Landslides in the study area in Taiwan (Photo (C) Daniel Hölbling) 


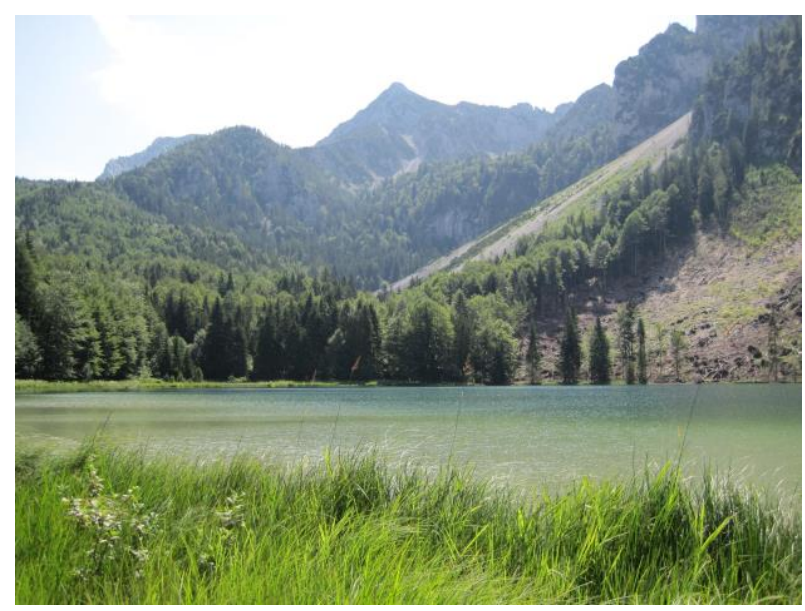

Figure 2. Landslides in the study area in Germany (Photo $@$ C www.frillensee.de)

Two stacks of complex TerraSAR-X SpotLight data were available for identifying and delineating unstable slopes in the areas of interest (AOIs). The employed image pairs were selected based on their perpendicular and temporal baselines (Tab. 1). TerraSAR-X amplitude images of the Taiwanese and German test site are shown in Fig. 3 and Fig. 4, respectively.

Table 1. Selected TerraSAR-X SpotLight image pairs and information about the interferometric stacks for AOI1 (Taiwan) and AOI2 (Germany)

\begin{tabular}{|c|c|c|c|}
\hline \multicolumn{4}{|c|}{ AOII - Track 149 (descending) } \\
\hline Orbit & Date & $\begin{array}{l}\text { Bperp } \\
{[\mathrm{m}]}\end{array}$ & $\begin{array}{l}\text { Btemp } \\
\text { [days] }\end{array}$ \\
\hline 23028 & 09/08/2011 & \multirow{2}{*}{$-36,01$} & \multirow{2}{*}{11} \\
\hline 23195 & 20/08/2011 & & \\
\hline \multicolumn{4}{|c|}{ AOI2 - Track 93 (descending) } \\
\hline Orbit & Date & $\begin{array}{l}\text { Bperp } \\
{[\mathrm{m}]}\end{array}$ & $\begin{array}{l}\text { Btemp } \\
\text { [days] }\end{array}$ \\
\hline 7608 & $28 / 10 / 2008$ & \multirow{2}{*}{266,94} & \multirow{2}{*}{22} \\
\hline 7942 & 19/11/2008 & & \\
\hline
\end{tabular}

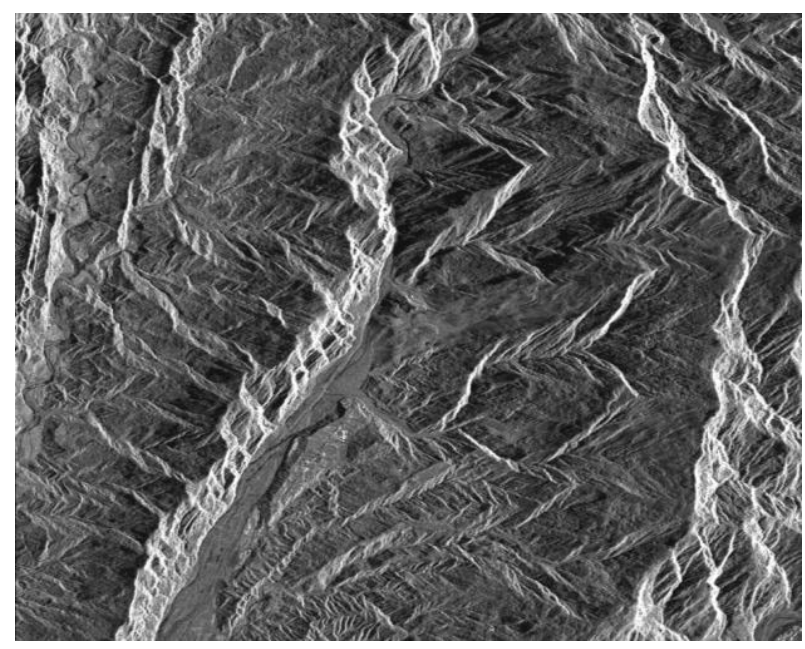

Figure 3. TerraSAR-X amplitude image of AOII

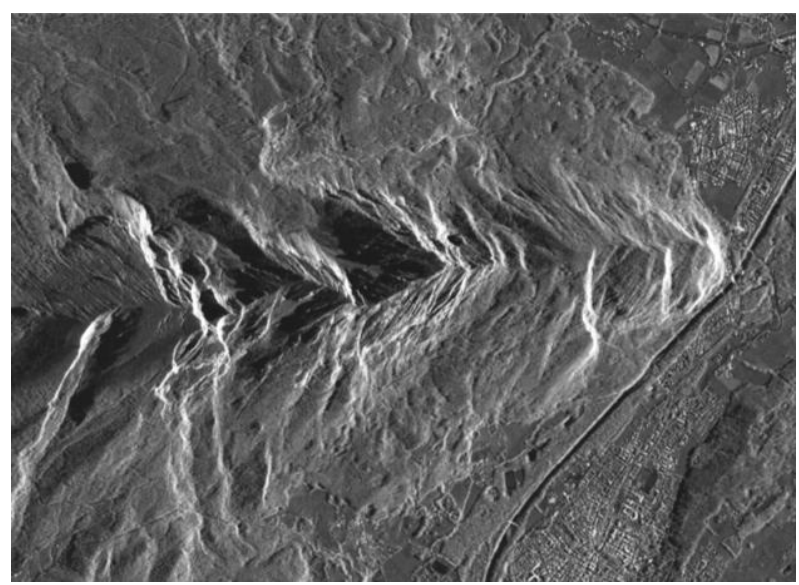

Figure 4. TerraSAR-X amplitude image of AOI2

\section{METHODOLOGY}

\subsection{Interferogram formation and estimation of coherence}

Initially, the available image pairs were co-registered to each other. Classical differential SAR Interferometry (DInSAR) was then applied for the formation of singlepair interferograms. As only one image pair was used per test site, temporal and spatial atmospheric noise contributions could not be removed from the interferograms. After the subtraction of the topographic phase, the interferogram was filtered using a modified version of the Goldstein method [8], which is implemented in NEST (Next ESA SAR Toolbox). By applying this filtering technique, the interferometric fringes appear sharper due to the fact that the peaks in the spectrum, which in turn are generated by the fringes, are weighted higher than their surroundings [9]. Subsequently, the coherence estimation operator was used to compute the coherence images and multilooking (window size $5 \times 5$ ) was applied to reduce inherent speckle noise. The filtered interferograms and coherence images were finally geocoded using the Range Doppler Terrain Correction operator and stored as GeoTiff. All processing steps were carried out using the software NEST.

\subsection{Identification and delineation of unstable slopes using object-based image analysis}

The obtained interferograms and coherence images were integrated in eCognition (Trimble Geospatial) software and a mean filter (window size $3 \times 3$ ) was applied to the interferograms to reduce the inherent noise in the first step. Subsequently, image objects were derived by applying the multiresolution segmentation [10] on the filtered interferogram. The reduced noise in the filtered interferograms allowed producing more homogenous image objects than if using the original interferogram, thus leading to better delineation of single fringes. A rule-based classification scheme was then implemented 
considering especially the spectral information of image objects but also geometry and contextual properties. In the course of this, high coherence values were used in the first instance to isolate areas, where interferometric fringes can be observed. As adjacent fringes showed very different spectral values (darker/brighter) in the interferograms, both comparatively high and low mean differences to neighboring objects were then taken into account for the identification of a sequence of fringes, i.e. unstable areas. Geometrical features, e.g. length/width ratio, and contextual properties, e.g. relative border to the neighboring object, were considered for the elimination of false positives. The same approach was applied for both test sites with only minor adaptations of classification thresholds. The workflow for the detection of unstable slopes is shown in Fig. 5.

\section{Interferogram formation and estimation of coherence}

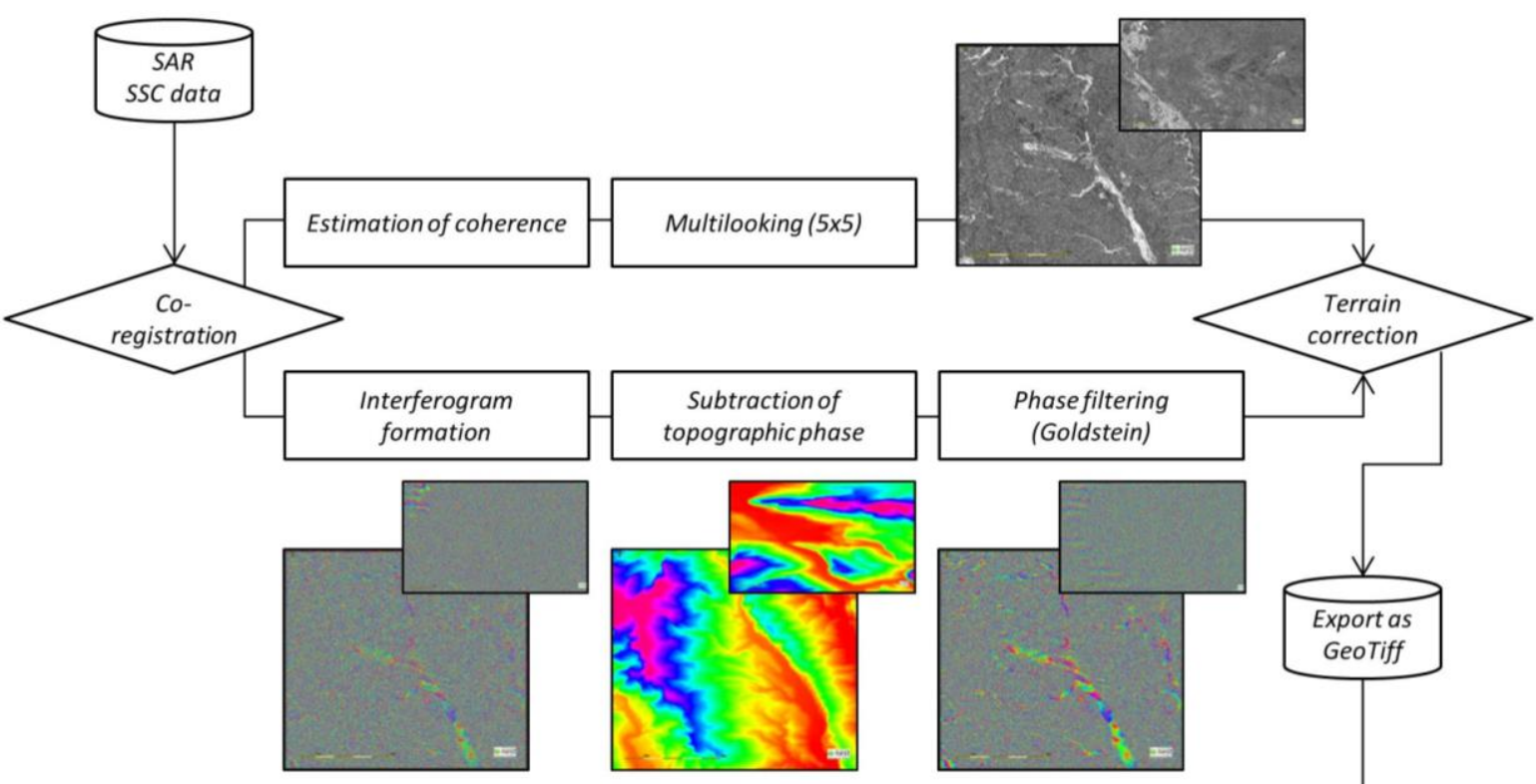

\section{Object-based image analysis}

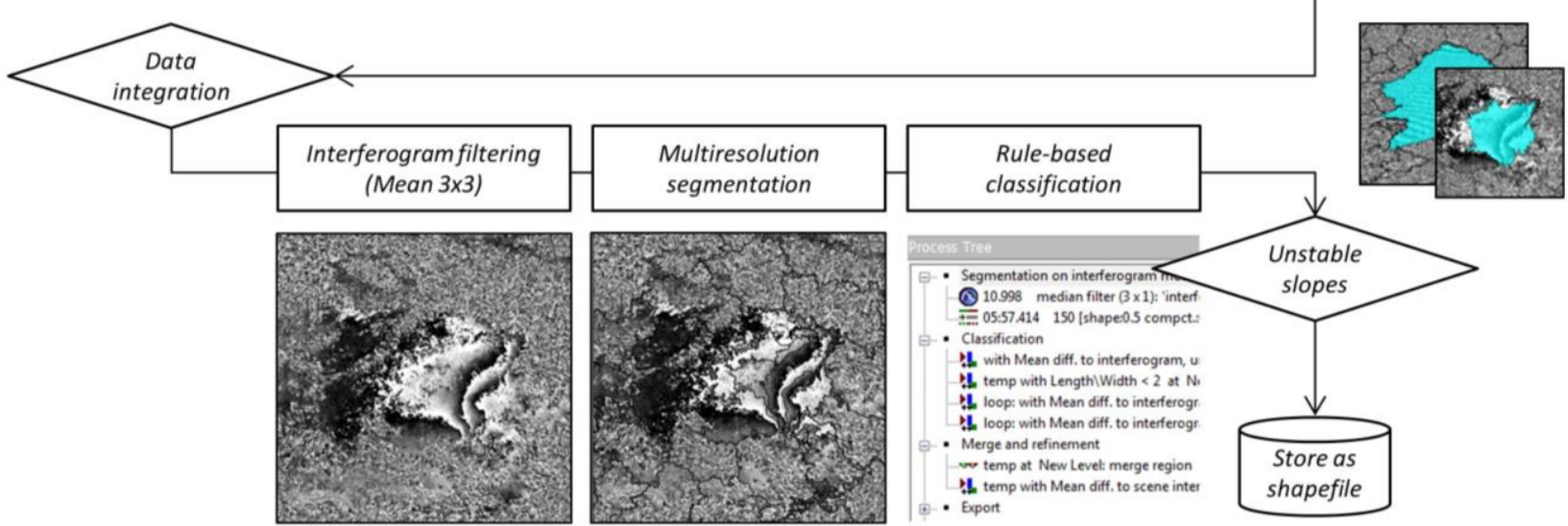

Figure 5. Workflow for the semi-automated detection of unstable slopes 


\section{RESULTS AND DISCUSSION}

Three unstable slopes were semi-automatically detected in the area of interest in Taiwan (Fig. $6-a, b, c)$ and two active slopes were identified in the test site in Germany (Fig. $7-$ a, b). The delineated slopes in the first study site form parts of older landslides and indicate regions where movement is still occurring, or are located in the major river bed where sediment is transported downstream. A talus slope (Fig. 7 - a) and related sediment transport has been identified in the second area of interest.
The second delineated slope in area two (Fig. 7 - b) might indicate an active slow-moving landslide, but the detected fringes could also be attributed to temporal or spatial de-correlation of the used InSAR data stacks. The interferometric fringes for both study sites are presented in Fig. 6 and in Fig. 7 respectively, taking into account that each colour cycle corresponds to a deformation gradient of 1.5 centimetres. The figures additionally show manually derived polygons, which were created for validation purposes using the SAR interferograms as data source.
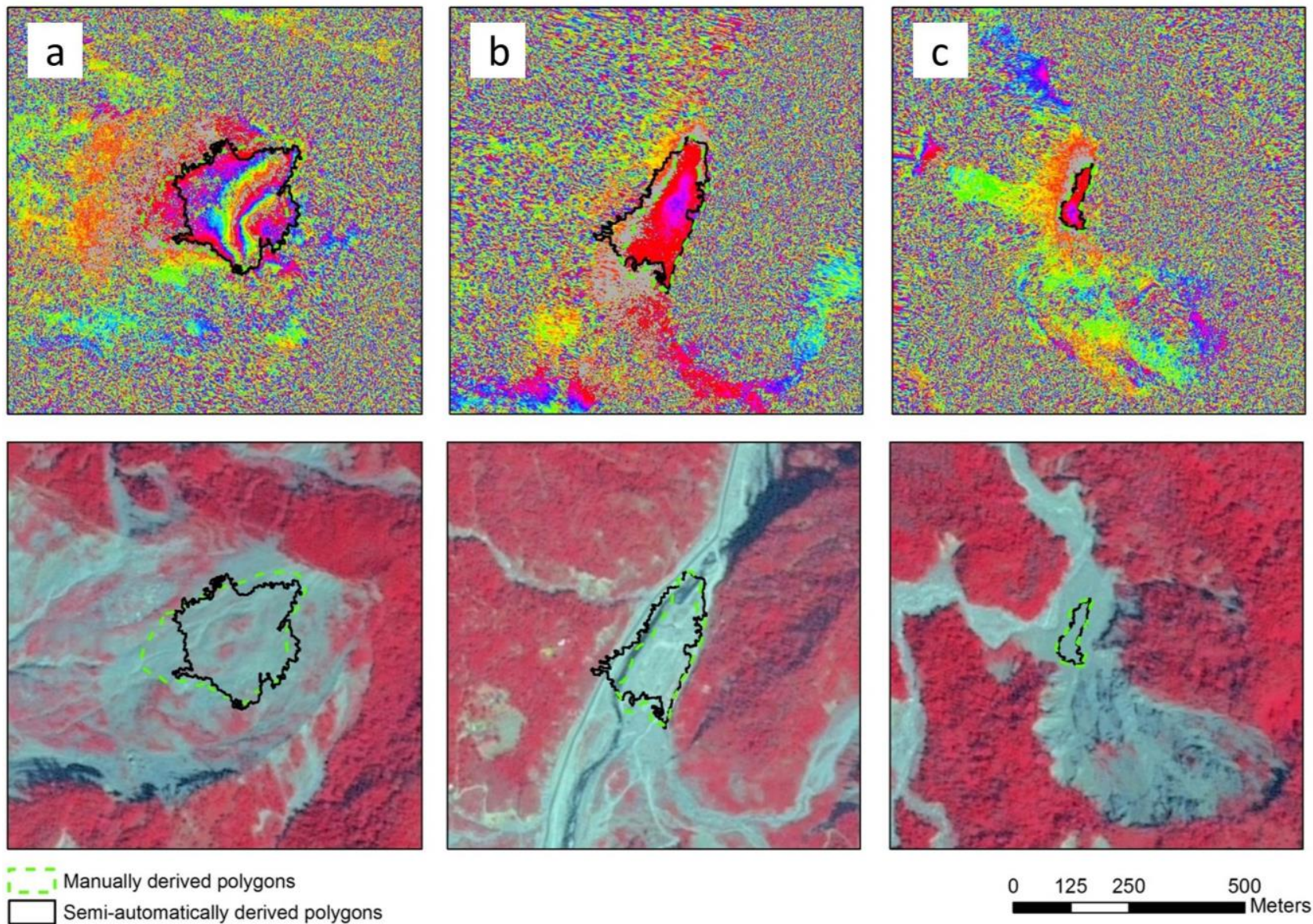

Manually derived polygons

Semi-automatically derived polygons

Figure 6. Results for the test site in Taiwan $(a, b, c)$. The black polygons indicate semi-automatically detected unstable slopes; the green outline delineates manually derived landslide polygons. A SPOT-5 image (band combination 3-2-1) is used as background layer. 

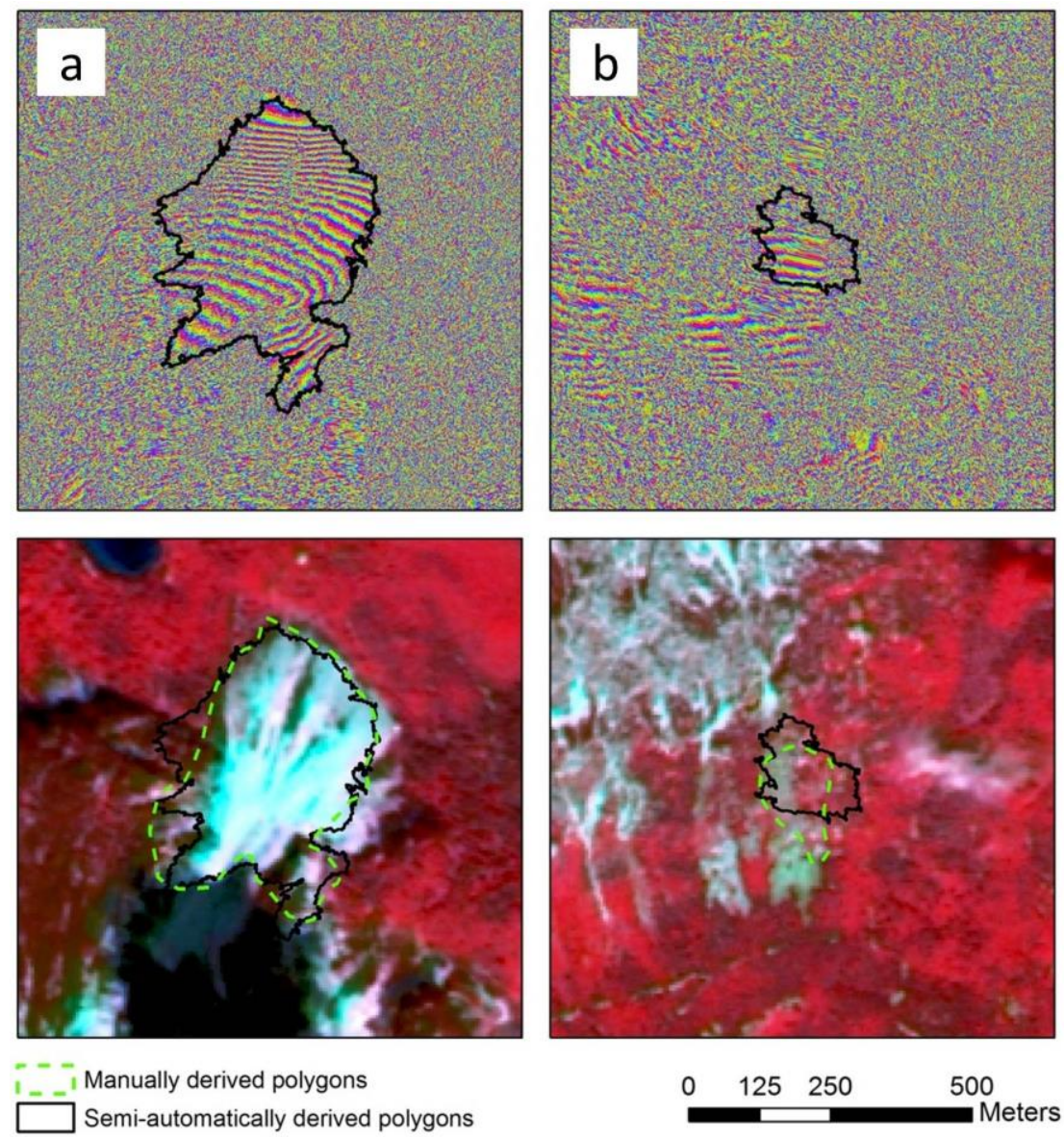

Figure 7. Results for the test site in Germany $(a, b)$. The black polygons indicate semi-automatically detected unstable slopes; the green outline delineates manually derived landslide polygons. A SPOT-5 image (band combination 3-2-1) is used as background layer.

Results were quantitatively compared to manually derived polygons, in order to evaluate the performance of the developed method. Tab. 2 gives an overview on the areal extent covered by the detected unstable slopes and the spatial overlap between the reference and the classification.

Table 2. Areal extent covered by the semi-automatically and manually derived unstable slopes and spatial overlap between these two results

\begin{tabular}{|l|l|l|l|l|}
\hline & $\begin{array}{l}\text { Reference } \\
{[\text { ha] }}\end{array}$ & $\begin{array}{l}\text { Classification } \\
{[\text { ha] }}\end{array}$ & $\begin{array}{l}\text { Spatial } \\
\text { overlap } \\
{[\text { [ha] }}\end{array}$ & $\begin{array}{l}\text { Spatial } \\
\text { overlap } \\
{[\%]}\end{array}$ \\
\hline AO1 \\
\hline$(a)$ & 6.3 & 4.95 & 4.62 & 73.3 \\
\hline$(b)$ & 2.95 & 3.32 & 2.54 & 86.1 \\
\hline$(c)$ & 0.58 & 0.44 & 0.44 & 75.9 \\
\hline $\boldsymbol{A O I 2}$ & 12.68 & 12.48 & 11.24 & 88.6 \\
\hline$(a)$ & 2.01 & 1.14 & 56.7 \\
\hline$(b)$ & 1.72 & 2
\end{tabular}

\section{CONCLUSIONS}

This study shows that object-based image analysis can be applied for the semi-automated delineation of unstable slopes and landslides using SAR interferometric products. The developed approach may be useful for supporting the investigation of active landslides, or for adding information on moving subareas to existing landslide inventories. The object-based delineation of unstable slopes may further provide relevant information (e.g. spatial extent of landslide activity) for risk assessment and landslide forecasting.

\section{ACKNOWLEDGMENTS}

The research leading to these results has received funding from the Austrian Science Fund (FWF) through the project "iSLIDE - Integrated Semi-Automated Landslide Delineation, Classification and Evaluation" (FWF-P25446-N29). 


\section{REFERENCES}

1. Debella-Gilo, M. \& Kääb, A. (2012). Measurement of Surface Displacement and Deformation of Mass Movements Using Least Squares Matching of Repeat High Resolution Satellite and Aerial Images. Remote Sensing 4(1), 43-67.

2. Blaschke, T. (2010). Object-based image analysis for remote sensing. ISPRS International Journal of Photogrammetry and Remote Sensing 65(1), 2-16.

3. Martha, T.R., Kerle, N., Jetten, V., van Westen, C.J. \& Kumar, K.V. (2010). Characterising spectral, spatial and morphometric properties of landslides for semi-automatic detection using object-oriented methods. Geomorphology 116(1-2), 24-36.

4. Stumpf, A. \& Kerle, N. (2011). Object-oriented mapping of landslides using Random Forests. Remote Sensing of Environment 115(10), 25642577.

5. Hölbling, D., Füreder, P., Antolini, F., Cigna, F., Casagli, N. \& Lang, S. (2012). A Semi-Automated Object-Based Approach for Landslide Detection Validated by Persistent Scatterer Interferometry Measures and Landslide Inventories. Remote Sensing 4(5), 1310-1336.

6. Plank, S., Hölbling, D., Eisank, C., Friedl, B., Martinis, S. \& Twele, A. (2015). Comparing object-based landslide detection methods based on polarimetric SAR and optical satellite imagery - a case study in Taiwan. $7^{\text {th }}$ International Workshop on Science and Applications of SAR Polarimetry and Polarimetric Interferometry, POLinSAR 2015, 27-30 January, Frascati, Italy.

7. Wu, C.-H., Chen, S.-C. \& Feng, Z.-Y. (2014). Formation, failure, and consequences of the Xiaolin landslide dam, triggered by extreme rainfall from Typhoon Morakot, Taiwan. Landslides 11(3), 357-367.

8. Goldstein, R. \& Werner, C. (1998). Radar interferogram filtering for geophysical applications. Geophysical Research Letters 25(21), 4035-4038.

9. Next ESA SAR Toolbox. Online User Manual. https://earth.esa.int/documents/507513/1077939/ne st+user+manual+5.1, [Accessed March 2015].

10. Baatz, M. \& Schäpe, M. (2000). Multiresolution segmentation - An optimization approach for high quality multi-scale image segmentation. In $\mathbf{J}$. Strobl, T. Blaschke \& G. Griesebner (Eds.), Angewandte Geographische InformationsVerarbeitung XII. Heidelberg: Wichmann, pp. $12-$ 23. 